\title{
En bloc removal of a colonic polyp using progressive polyp contraction with underwater endoscopic mucosal resection: the PP-CUE technique
}

Underwater endoscopic mucosal resection (uEMR) is an injectionless form of EMR that allows intestinal adenomas to be safely resected without creating a submucosal cushion [1]. Proponents of uEMR cite safety and effectiveness of the technique, as well as speed and higher en bloc and $\mathrm{R} 0$ resection rates [2]. Furthermore, mucosal lesions contract underwater, facilitating en bloc capture of lesions larger than the snare opening [3].

Despite this, suboptimal en bloc resection rates (89\%) have been reported among intermediate-sized (10-20 mm) lesions, with even lower $\mathrm{R} 0$ resection rates (69\%) [4]. This suggests that the snares used were too small, resulting in piecemeal or incomplete removal. We have developed a technique - progres-

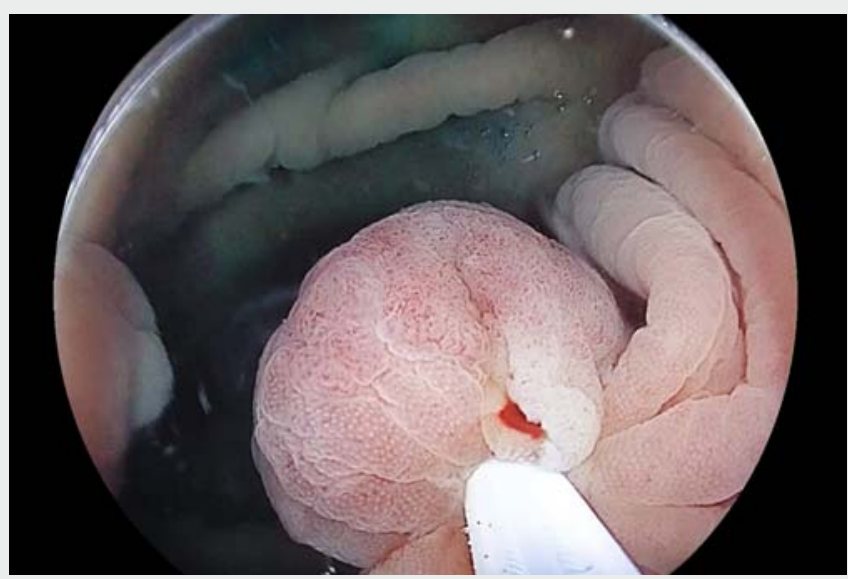

Video 1 Demonstration of progressive polyp contraction with underwater endoscopic mucosal resection of a colonic polyp.
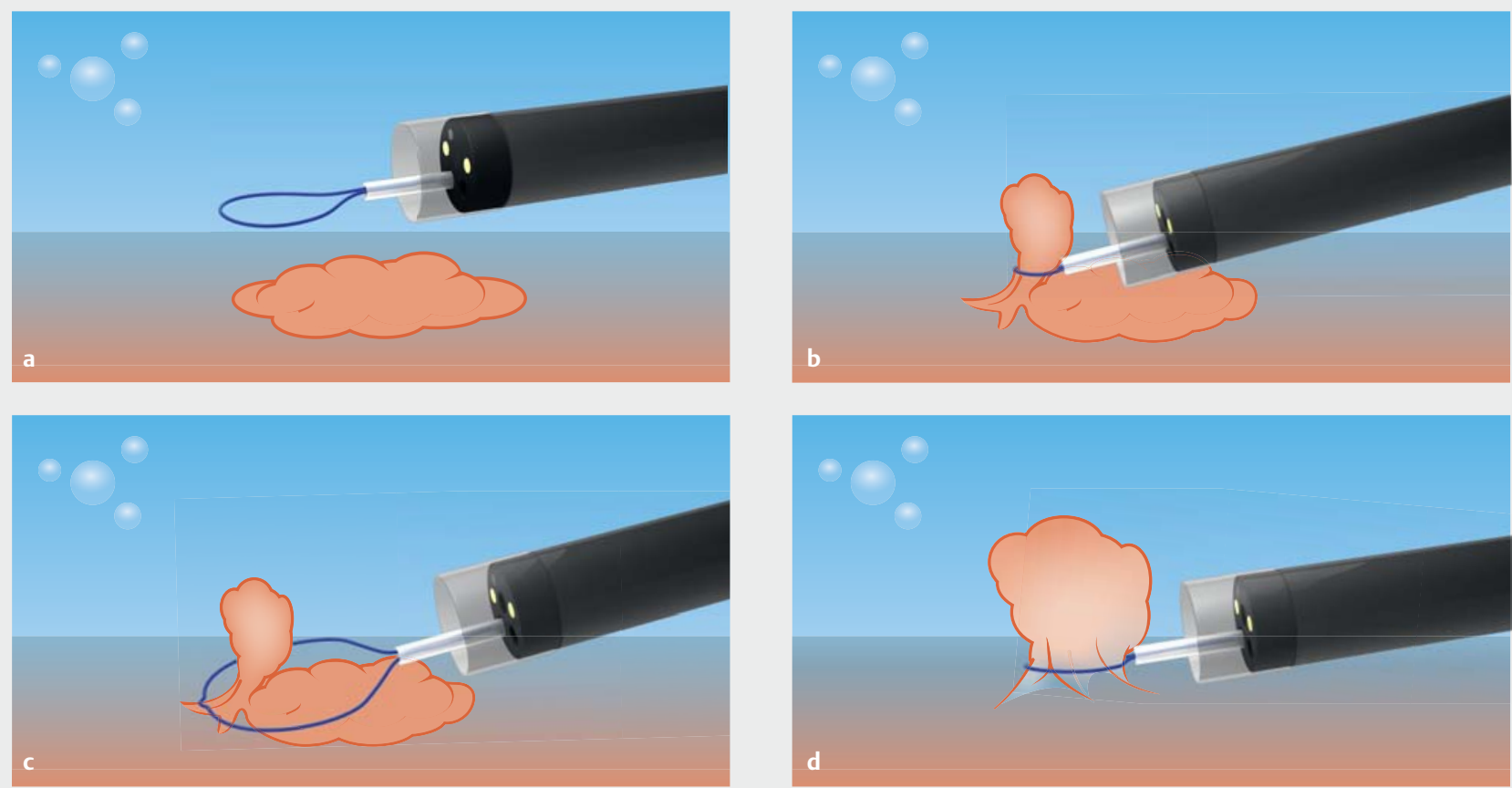

Fig. 1 Technique stages of progressive polyp contraction with underwater endoscopic mucosal resection (PP-CUE). a The intestinal lumen is completely deflated and filled with water until the lesion visibly floats. The tip of a stiff-wire colonic snare is embedded $1-2 \mathrm{~mm}$ outside the proximal border and maximally opened over the lesion to capture as much polyp as possible. $\mathbf{b}$ The snare is gently closed until resistance is felt in the snare handle, compressing the entrapped tissue into a 0 -Isp morphology. $\mathbf{c}$ The snare is slowly reopened and the remaining polyp tissue is ensnared. d After confirming capture of the entire lesion, including 1-2 mm of normal surrounding mucosa, the snare is maximally closed. Mobility is confirmed by moving the snare catheter back and forth. Diathermy is applied and the lesion is transected quickly. 

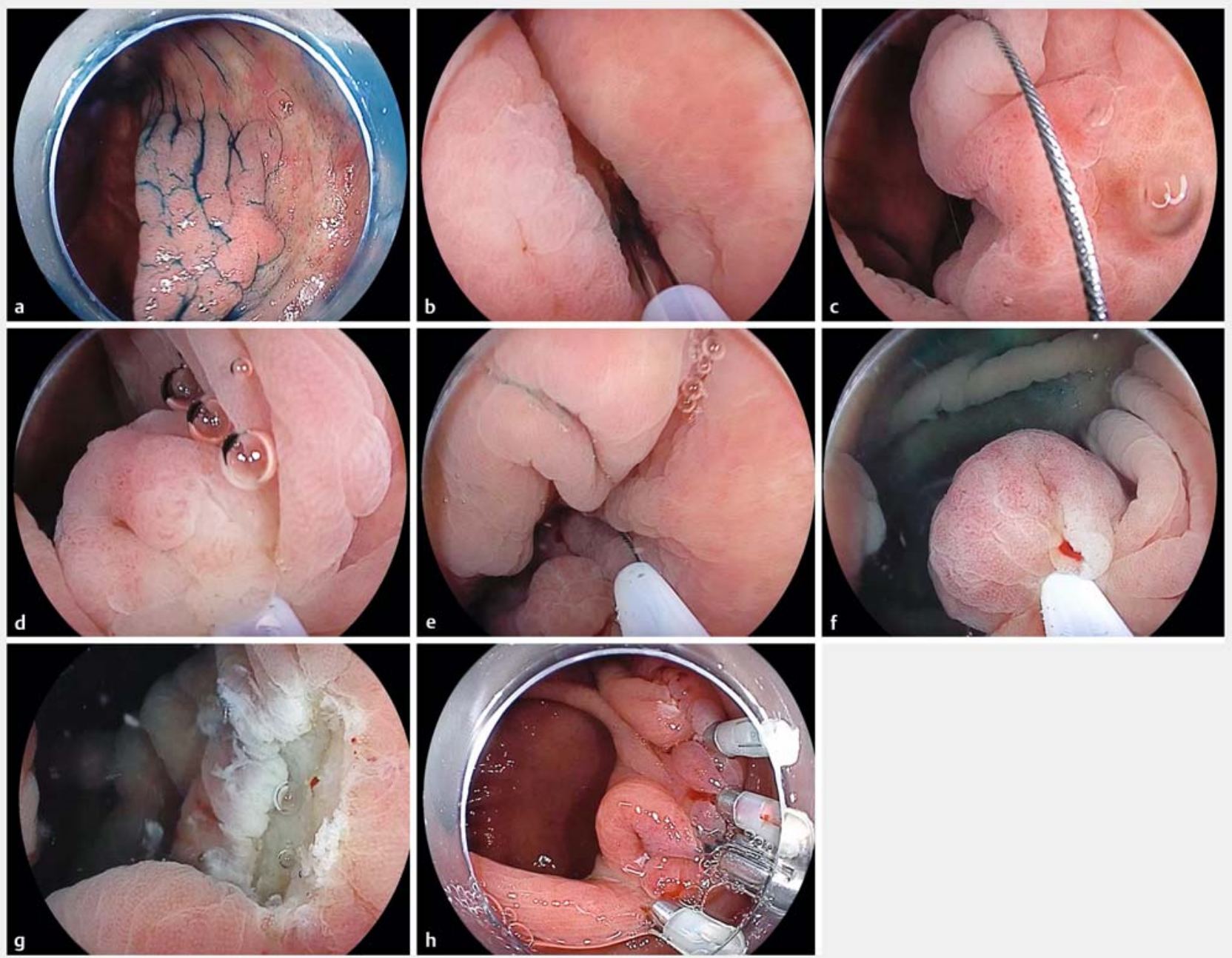

Fig. 2 Endoscopic images of the progressive polyp contraction with underwater endoscopic mucosal resection (PP-CUE) technique. a 20-mm Paris 0-lla, granular, JNET2A/NICEII laterally spreading lesion (LSL) in the ascending colon. b Deflated, water-filled intestinal lumen with the tip of the colonic snare embedded 1-2 mm outside the proximal border of the LSL, over normal mucosa. c The maximally opened snare over a portion of the LSL. $\mathbf{d}$ The closed snare, compressing entrapped tissue into a 0 -Isp morphology. $\mathbf{e}$ The reopened snare over the remaining LSL tissue. $\mathbf{f}$ The maximally closed snare with complete capture of the LSL, with a 1-2 mm border of normal surrounding mucosa. $\mathbf{g}$ The post-resection defect following PP-CUE. h Complete closure of the defect with four hemoclips.

sive polyp contraction with underwater EMR (PP-CUE) - for removing neoplasms

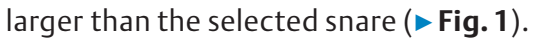
First, the intestinal lumen is completely deflated of air, then filled with water until the lesion floats. A stiff-wire snare, slightly larger than the estimated lesion size, is inserted and the tip is embedded $1-2 \mathrm{~mm}$ outside the proximal border of the lesion over normal tissue. The snare is slowly opened, attempting to capture as much of the lesion as possible, and then gently closed until resistance is felt, compressing the entrapped tissue into a 0 -Isp morphology. The snare is slowly reopened and the remaining tissue is ensnared. After visually confirming capture of the entire lesion, including 1 $2 \mathrm{~mm}$ of normal surrounding mucosa, the snare is maximally closed. The snare catheter is moved back and forth to confirm mobility, diathermy is applied (ESG-100, Monopolar, Cut 1, Level 15; Olympus Corp., Tokyo, Japan), and the lesion is transected quickly.

A 20-mm, Paris lla, granular, JNET 2A/ NICEIl laterally spreading lesion in the ascending colon was resected using the PP-CUE technique ( Fig.2, $>$ Video $\mathbf{1}$ ). The lesion was removed en bloc with no evidence of residual adenoma or adverse events. Pathology results confirmed R0 resection of a low-grade tubular adenoma.

Endoscopy_UCTN_Code_TTT_1AQ_2AD

\section{Competing interests}

The authors declare that they have no conflict of interest. 
Ralph F. Lee ${ }^{1,2}$, Tatsuma Nomura', Yoshikazu Hayashi ${ }^{1}$, Masahiro Okada ${ }^{1}$, Hironori Yamamoto $^{1}$

1 Department of Medicine, Division of Gastroenterology, Jichi Medical University, Shimotsuke, Japan

2 Department of Medicine, Division of Gastroenterology, University of Ottawa, Ottawa, Ontario, Canada

\section{Corresponding author}

\section{Hironori Yamamoto, MD, PhD}

Department of Medicine, Division of Gastroenterology, Jichi Medical University, 3311-1 Yakushiji, Shimotsuke, Tochigi 329-0498, Japan

Fax: +81-285-406598

ireef@jichi.ac.jp

\section{References}

[1] Binmoeller KF, Weilert F, Shah J et al. "Underwater" EMR without submucosal injection for large sessile colorectal polyps (with video). Gastrointest Endosc 2012; 75: 10861091

[2] Spadaccini M, Fuccio L, Lamonaca L et al. Underwater EMR for colorectal lesions: a systematic review with meta-analysis (with video). Gastrointest Endosc 2019; 89: 11091116 e4

[3] Binmoeller KF. Underwater EMR without submucosal injection: Is less more? Gastrointest Endosc 2019; 89: 1117-1119

[4] Yamashina T, Uedo N, Akasaka T et al. Comparison of underwater vs conventional endoscopic mucosal resection of intermediate-size colorectal polyps. Gastroenterology 2019; 157: 451-461 e2
Bibliography

Endoscopy 2020; 52: E434-E436

DOI 10.1055/a-1147-1240

ISSN 0013-726X

published online 12.5.2020

(c) 2020. Thieme. All rights reserved.

Georg Thieme Verlag KG, Rüdigerstraße 14,

70469 Stuttgart, Germany

\section{ENDOSCOPY E-VIDEOS}

https://eref.thieme.de/e-videos

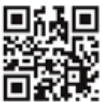

Endoscopy E-Videos is a free access online section, reporting on interesting cases and new techniques in gastroenterological endoscopy. All papers include a high quality video and all contributions are freely accessible online.

This section has its own submission website at

https://mc.manuscriptcentral.com/e-videos 